\title{
The Association between Serum Lipoxin A4 Level and Lupus Nephritis
}

\author{
HANAN A. TAHA, M.D.*; MAHMOUD FARID, M.D.*; MOHAMED A. ELFIKI, M.D.*; \\ KHALED S. MOHAMED, M.D.*; AYMAN S. SOLIMAN, M.D.** and HANAN M. FARHAN, M.D.***
}

The Departments of Internal Medicine*, Physiology** and Clinical Pathology***, Faculty of Medicine, Beni-Suef University, Egypt

\begin{abstract}
Background: Systemic Lupus Erythematosus (SLE) is an autoimmune connective tissue disorder with a wide range of clinical features, which predominantly affects females. Glomerulonephritis (GN) is a major determinant of the course and prognosis of SLE and is clinically evident in 40-83\% of patients. Lupus Nephritis (LN) affects from one-third to onehalf of lupus patients and accounts for significant morbidity and mortality. Lipoxins are produced locally at sites of inflammation by transcellular routes. Lipoxin biosynthesis has been described in many human and experimental diseases associated with cell contact, including glomerulonephritis, asthma, and rheumatoid arthritis. Yet, there is no gold standard for assessment of lupus nephritis up till now.
\end{abstract}

Aim of Study: The aim of this study is to assess the level of serum lipoxin A4 as a diagnostic biomarker in cases of SLE complicated with lupus nephritis and to evaluate its relation to pathogenesis of lupus nephritis and renal disease activity.

Patients and Methods: This study was conducted on fifty Egyptian patients with Lupus Nephritis (LN) and 10 healthy subjects as a control. Disease activity was assessed using Systemic Lupus Erythematosus Disease Activity Index (SLEDAI) and renal SLEDAI. Complete blood picture (CBC), ESR, Anti deoxyribonucleic acid (Anti-dsDNA) antibodies, Antinuclear Antibodies (ANA), quantitative determination of serum complements levels (C3, C4), complete urine analysis, 24 hours urinary proteins, serum creatinine, blood urea and Serum Lipoxin A4 $\left(\mathrm{LXA}_{4}\right)$ level by (ELISA) were done for all samples of the study groups. Renal biopsy, microscopic examination and pathological classification was performed for all patients.

Results: SLE patients with lupus nephritis showed a lower median level of serum $\mathrm{LXA}_{4}$ compared with the control group (7.7 Vs. $25.8 \mathrm{ng} / \mathrm{ml})$, with highly significant statistical difference $(p<0.001)$. Total SLEDAI and the renal SLEDAI, also were correlated with lipoxin A 4 level and showed no significant statistical correlation. No correlation was found between serum lipoxin $\mathrm{A} 4$ and, age, sex, disease duration, anti-dsDNA, $\mathrm{C} 3$ and $\mathrm{C} 4$, ESR, 24 urinary proteins, ANA and CBC parameters. The levels of serum lipoxin A4 did not show significant

Correspondence to: Dr. Hanan A. Taha, The Department of Internal Medicine, Faculty of Medicine, Beni-Suef University, Egypt statistical difference among all SLE patients and the drug history.

Conclusion: Serum $\mathrm{LXA}_{4}$ deficiency could be used as a noninvasive diagnostic biomarker for renal involvement in SLE patients.

Key Words: Lupus nephritis - Serum lipoxin A 4 - Systemic lupus erythematosus.

\section{Introduction}

SYSTEMIC Lupus Erythematosus (SLE) is a chronic, multifaceted inflammatory disease that affects every organ system of the body; the disease is protean in its manifestations and follows a relapsing and remitting course characterized by multisystem microvascular inflammation with the generation of autoantibodies [1]

Although the specific cause of SLE is unknown, multiple factors are associated with the development of the disease, including genetic, racial, hormonal, and environmental factors. Immune complexes form in the microvasculature, leads to complement activation and inflammation. Moreover, antibody-antigen complexes deposit on the basement membranes of skin and kidneys. In active SLE, this process has been confirmed based on the presence of complexes of nuclear antigens such as DNA, immunoglobulins, and complement proteins at these sites. Serum Antinuclear Antibodies (ANAs) are found in virtually all individuals with active SLE, and antibodies to native doublestranded DNA (dsDNA) are relatively specific for the diagnosis of SLE [2]. SLE frequently starts in women of childbearing age; the peak incidence occurs between the ages of 15 and 45 years, where the female-to-male ratio is about 9:1 [3]

The exact patho-aetiology of SLE remains elusive. Multiple genes contribute to disease susceptibility. The interaction of sex, hormonal milieu 
and the hypothalamo-pituitary-adrenal axis modifies this susceptibly and the clinical expression of the disease. Defective immune regulatory mechanism, such as the clearance of apoptotic cells and immune complexes, excess T-cell, defective B cell suppression are important contributors to the development of SLE. Finally, certain environmental factors are probably required to trigger the disease [4].

Complement activation mediates much of the characteristic end organ effects, but early complement components are required to protect against the development of SLE. Between $90 \%$ and $95 \%$ of $\mathrm{C} 4$ or $\mathrm{C} 1$ deficient individuals develop SLE and approximately $30 \%$ of $\mathrm{C} 2$ deficient individuals develop SLE [5].

Abnormal oestrogen metabolism has been demonstrated in patients with SLE of both sexes, with an increase in $16 \alpha$ hydroxylation of oestrone, the $16 \alpha$ metabolites are more potent and feminising oestrogens. Women with SLE also have low plasma androgens, including testosterone, dihydrotestosterone, Dehydroepiandrosterone (DHEA) [6]. The fact that most monozygotic twins are discordant for clinical SLE suggests that environmental factors play a role in disease pathogenesis [7].

Renal involvement in SLE is a common manifestation and a strong predictor of poor outcome. Clinically significant renal involvement ranges from asymptomatic urinary findings to nephritic syndrome and renal failure [8]. The huge capillary bed, along with the negatively charged basement membrane and the intricate functional capacity of the cells embedded in the glomerular apparatus and the conducting tubules, create an environment that is highly susceptible to inflammatory insults, caused by autoantibodies [9].

Autoimmunity plays a major role in the pathogenesis of lupus nephritis. The immunologic mechanisms include production of autoantibodies directed against nuclear elements. These autoantibodies form pathogenic immune complexes. Deposition of these immune deposits in the kidneys initiates an inflammatory response by activating the complement cascade and recruiting inflammatory cells that can subsequently be observed on biopsy specimens. Glomerular thrombosis is another mechanism that may play a role in pathogenesis of lupus nephritis, mainly in patients with antiphospholipid antibody syndrome, and is believed to be the result of antibodies directed against negatively charged phospholipid-protein complexes [1].
Lipoxins are produced locally at sites of inflammation by transcellular routes, involving interaction of neutrophils with platelets or resident tissue cells, such as epithelial cells, by one of at least three biosynthetic pathways. At mucosal surfaces, epithelial granulocyte interactions via the action of 15-Lipoxygenase (LO) on arachidonate generate intermediate eicosanoid products, which serve as substrates for Polymorph Nuclear Neutrophil (PMN) 5-LO, generating lipoxin A4 (LXA4) and Lipoxin B 4 (LXB 4). Within the vascular lumen, platelet-neutrophil interactions, involving neutrophil 5-LO and platelet 12-LO, generate lipoxins. In this setting platelets convert neutrophil-derived Leukotriene A4 (LTA4) to the lipoxin intermediate (5, 6 epoxytetraene) through the action of platelet 12-LO [11] .

Lipoxin biosynthesis has been described in many human and experimental diseases associated with cell-cell contact, including glomerulonephritis, asthma, and rheumatoid arthritis [12]. Lipoxins are putative endogenous "stop signals" that inhibit neutrophil recruitment and promote resolution of inflammation. Lipoxins display selective actions on specific leukocytes: Inhibiting activation of PMNs and eosinophils and activating monocytes and macrophages [13]. The aim of this study is to assess the level of serum lipoxin A4 as a diagnostic biomarker in cases of SLE complicated with lupus nephritis and to evaluate its relation to pathogenesis of lupus nephritis and renal disease activity.

\section{Patients and Methods}

Study design:

This present study was conducted on fifty Egyptian patients with Lupus Nephritis (LN) who were attending the outpatient clinic or admitted in the inpatient unit of the Internal Medicine Department in Beni-Suef University Hospital. They were diagnosed according to the American College of Rheumatology (ACR) revised criteria [14]. This study was done during the year 2017. A written consent was taken from each person included in this study whether in patients' group or normal control group.

The individuals were divided into 2 main groups:

I- Patients group: 50 patients with Lupus Nephritis (LN), they were 41 female patients $(82 \%)$ and 9 male patients (18\%). Their ages ranged from $18-50$ years with a mean of $(27.46 \pm 6.5)$ years.

II- Control group: 10 normal healthy individuals ( 6 females and 4 males) with age matching as a control as their ages were ranged from 18-48 years old with a mean of $(27.7 \pm 5.165)$ years. 


\section{Exclusion criteria:}

Patients with diabetes mellitus, malignancies, mixed connective tissue disease and history of renal dialysis.

\section{Methods:}

Patients and controls were subjected to the following:

I- Thorough history taking: Including; constitutional symptoms, (eyes, ears, nose and throat) symptoms, mucocutaneous symptoms, neuropsychiatric symptoms, articular symptoms, muscular symptoms, cardiopulmonary symptoms, genitourinary symptoms and drug history.

II- Full clinical examination: Including; weight and height, vital signs, (eyes and mouth) examination, skin examination, muscle examination, articular examination, chest examination, cardiac examination, neurological examination, abdominal examination, examination of the lymph nodes and peripheral pulses.

III-Assessment of systemic lupus erythematosus disease activity: Using Systemic Lupus Erythematosus Disease Activity Index (SLEDAI) and Renal Systemic Lupus Erythematosus Disease Activity Index (Renal SLEDAI) [15]

\section{$I V$ - Laboratory investigations:}

- Sample collection: An overnight fasting (810 hours) venous blood sample was collected from each subject using a sterile plastic syringe. One portion of the collected blood was taken on Ethylene-Diamine-Tetra-Acetic Acid (EDTA) containing tube for CBC. The remainder of the blood was allowed to clot for 10-20 minutes at room temperature then centrifuged for 20 minutes at the speed of 2000-3000r.p.m to separate the serum. One portion of the serum was used immediately for the measurement of creatinine. The other portion was stored in epindorph tubes in a deep freeze at $-20^{\circ} \mathrm{C}$ till tested for other investigations. Serum samples are stable for 3 months at $-20^{\circ} \mathrm{C}$. 24 hours urine collection were taken from patients for complete urine analysis and 24 hours urinary proteins.

- Biochemical assays: Complete blood picture (CBC), ESR, serum creatinine, blood urea, complete urine analysis, 24 hours urinary proteins, serum albumin, AST, ALT, Antinuclear Antibodies (ANA), Anti deoxyribonucleic acid (Anti-dsDNA) antibodies and Quantitative determination of serum complement levels $(\mathrm{C} 3, \mathrm{C} 4)$.

Serum Lipoxin A4 level was measured by Enzyme-Linked Immunosorbent Assay (ELISA) technique using an ELISA kit with product No.: EA45 (purchased from Oxford Biomedical Research Inc., USA). Serum was stored at $20^{\circ} \mathrm{C}$ before processing and equilibrated with room temperature before testing. LXA4 was extracted from serum before analysis using C18 Sep-Pak Light Column (\#23501; Waters Corporation).

All previously mentioned biochemical assays were done for all samples of the study groups. For all biochemical assays, the manufacturer instructions were followed.

V- Renal biopsy and microscopic examination: Renal biopsy and microscopic examination were done for all patients and the renal pathology was classified according to the revised International Society of Nephrology/Renal Pathology Society (ISN/RPS) classification of nephritis [16]

Statistical analysis: Data was collected, verified, revised then edited on personal computer. Data were coded and entered using the statistical package SPSS (Statistical Package for the Social Science; SPSS Inc., Chicago, IL, USA) Version 22. $p$-values less than 0.05 were considered as statistically significant.

Receiver Operating Characteristics (ROC) curves were used to discriminate positive from negative results. The Area Under the Curve (AUC) can range from 0.5 to 1 and diagnostic test that approaches 1 indicates a perfect discriminator. ROC curves also determined the threshold value for optimal sensitivity and specificity, which was constructed by calculating the true positive fraction (sensitivity percent) and the false positive fraction (100-specificity) of markers at several cutoff points.

\section{Results}

Data of the present study showed that the total number of patients were fifty, nine of them were male patients $(18 \%)$ and forty-one were female patients $(82 \%)$. Patients ages ranged from 18 to 50 years with a mean age of $(27.46 \pm 6.5)$ years. The majority of patients ages were below 30 years (38 patients; $76 \%$ ) while (12 patients; $24 \%$ ) their ages were above 30 years. The SLE duration ranged from 1 to 144 months with a mean of $(39.9 \pm 35.6)$ months. The lupus nephritis duration ranged from 1 to 108 months with a mean of $(25.6 \pm 23)$ months.

In addition, our study results showed that hypertension and nephritic presentations were the highest clinical presentations among the lupus nephritis patients $(80 \%$ and $62 \%)$ respectively while thrombotic events and sensory affection were the lowest clinical presentations $(12 \%$ and $4 \%)$ respectively Fig. (1). 
Our results demonstrated elevated mean systolic blood pressure among patients' group as it is ranged from 100 to $220 \mathrm{mmHg}$ with a mean of $(159.2 \pm 27.5)$ $\mathrm{mmHg}$. In addition, there was elevated mean diastolic blood pressure which ranged from 70 to $120 \mathrm{mmHg}$ with a mean of $(94.6 \pm 11.5) \mathrm{mmHg}$.

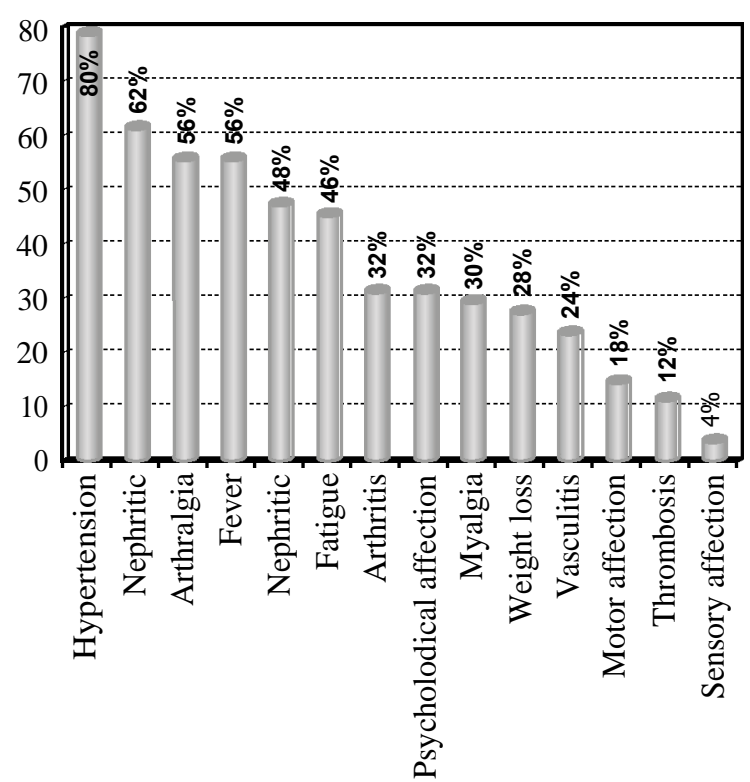

Fig. (1): Percentage of presence of each clinical finding among lupus nephritis patients.

Table (1): Description of laboratory investigations among lupus nephritis patients.

\begin{tabular}{lllll}
\hline Investigation & Min. & Max. & Mean & SD \\
\hline Kidney functions: & & & & \\
Blood Urea (mg/dl) & 16 & 230 & 62.18 & 49.2 \\
$\quad$ Serum Creatinine (mg/dl) & 0.5 & 6.8 & 1.6 & 1.3 \\
24-hour urinary protein (mg/l) & 1000 & 7000 & 2750 & 1540 \\
& & & & \\
Liver functions: & 1.3 & 4 & 3.3 & 3.1 \\
Serum Albumin (gm/dl) & 10 & 102 & 29.2 & 19.1 \\
AST (u/l) & 6 & 87 & 42.74 & 15.31 \\
ALT (u/l) & & & & \\
CBC \& ESR: & 6.5 & 13 & 9.6 & 1.5 \\
Hb (gm/dl) & 6 & 30 & 17.3 & 5.4 \\
Lymphocytes \% 3 / & 15 & 640 & 212.7 & 119.7 \\
Platelet count $(10$ & 37 & 150 & 84.8 & 26.7 \\
ESR & 2.1 & 16 & 6.74 & 2.89 \\
WBCs & & & & \\
\hline
\end{tabular}

The present study results showed that the serum creatinine level in patients' group ranged from $0.5-6.8 \mathrm{mg} / \mathrm{dl}$ with a mean of $1.6 \pm 1.3 \mathrm{mg} / \mathrm{dl}$. These results are due to presence of patients with renal impairment as serum creatinine level exceeded $1.5 \mathrm{mg} / \mathrm{dl}$ in 10 cases out of 50 cases in patients' group but none of them started hemodialysis. The 24-hours urinary protein level ranged from 1000 to $7000 \mathrm{mg} / \mathrm{l}$ with a mean of $2750 \pm$ $1540 \mathrm{mg} / \mathrm{l}$ (Table 1).
Data of the present work regarding casts in urine analysis among lupus nephritis patients demonstrated that $46 \%$ of patients showed no urinary casts while $34 \%$ of patients showed urinary granular casts. The lowest two percentages ( $2 \%$ and $4 \%$ ) of patients had hyaline casts \& cells and granular casts $\&$ cells) respectively (Table 2 ).

Table (2): Description of casts in urine analysis among lupus nephritis patients.

\begin{tabular}{lcc}
\hline & \multicolumn{2}{c}{ Study group $(\mathrm{n}=50)$} \\
\cline { 2 - 3 } Casts & Number & $\%$ \\
\hline No casts & 23 & 46 \\
Granular & 17 & 34 \\
Hyaline & 4 & 8 \\
Hyaline + granular & 3 & 6 \\
Hyaline + cells & 1 & 2 \\
Gran + cells & 2 & 4 \\
\hline
\end{tabular}

Our study results as regards quantitative determination of serum complement levels; C3 \& C4 among lupus nephritis patients; serum $\mathrm{C} 3$ levels were low in $50 \%$ of patients and normal in rest of patients. Also, serum C4 levels were low in 64\% of patients and normal in rest of patients (Table 3). Antinuclear Antibodies (ANA) was positive in all patients while Anti deoxyribonucleic acid (AntidsDNA) antibodies was positive in $84 \%$ of patients.

Table (3): Description of complement factors findings among lupus nephritis patients.

\begin{tabular}{ccc}
\hline \multirow{2}{*}{$\begin{array}{l}\text { Complement } \\
\text { factors }\end{array}$} & \multicolumn{2}{c}{ Study group $(\mathrm{n}=50)$} \\
\cline { 2 - 3 } & Number & $\%$ \\
\hline C3 $(\mathrm{mg} / \mathrm{dl}):$ & & \\
Low & 25 & 50 \\
Normal & 25 & 50 \\
C4 $(\mathrm{mg} / \mathrm{dl}):$ & & \\
Low & 32 & 64 \\
Normal & 18 & 36 \\
\hline
\end{tabular}

Data of our study demonstrated that the total (SLEDAI) score was ranged from 5-38 with a mean of 19.12 \pm 6.7 . As regards the renal (SLEDAI) score was ranged from $0-16$ with a mean of $10.4 \pm 4$.8.

Our study data as regards renal biopsy and microscopic examination showed that $56 \%$ of patients had chronic inflammatory affection while $22 \%$ of patients had active affection and the remaining $22 \%$ of patients had active on top of chronic affection.

Renal pathology was classified according to the revised International Society of Nephrology/ Renal Pathology Society (ISN/RPS) classification of nephritis and showed that $52 \%$ of lupus nephritis 
patients belongs to class III, 34\% of lupus nephritis patients belongs to Class IV while the remaining $14 \%$ of lupus nephritis patients belongs to class V according to (ISN/RPS) classification.

Data of the current study demonstrated that all members of patients group were on Corticosteroid \& Hydroxychloroquine while, forty-two patients $(44 \%)$ were on Azathioprine. Also, thirty-eight patients $(76 \%)$ were on antihypertensive drugs, twelve patients $(24 \%)$ were on lipid lowering drugs, eighteen patients $(36 \%)$ received Acetylsalicylic acid and five patients $(10 \%)$ received Warfarin.

Our patients received steroids in a dose ranged 10 to $40 \mathrm{mg} /$ day with mean of $20 \pm 9.34$, Hydroxychloroquine dose ranged from 200 to $400 \mathrm{mg} /$ day with mean of 294. 11 \pm 115.4 , Azathioprine dose ranged from 50 to $150 \mathrm{mg} /$ day with mean of $88.6 \pm$ 37.4 .

Our study results showed that there is high statistically significant decline in serum level of lipoxin A4 in patients' group $(7.7 \pm 4.6) \mathrm{ng} / \mathrm{ml}$ as compared to control group $(25.8 \pm 21.7) \mathrm{ng} / \mathrm{ml}$ $p<0.001$ Fig. (2).

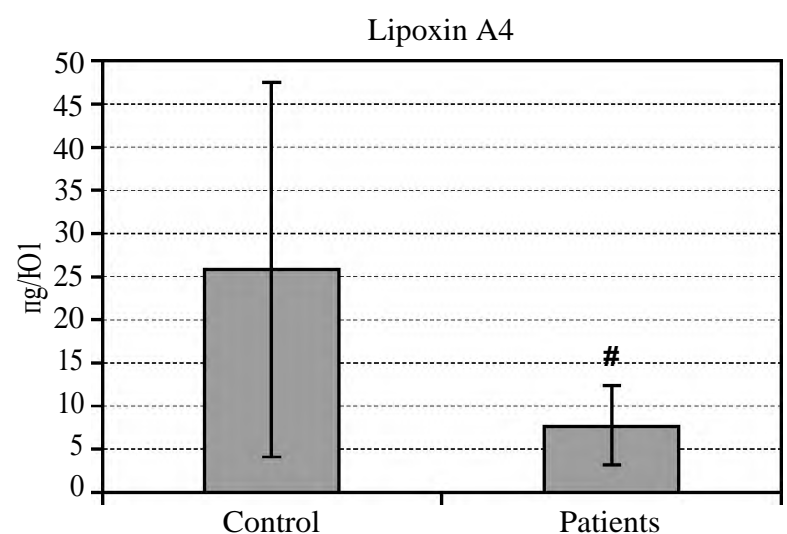

Fig. (2): Comparison between patients' group and control group regarding the serum lipoxin A4 level (ng/ml)

\#: Significant as compared to control group $p<0.001$.

Current study results showed no statistically significant differences in serum lipoxin A 4 level among lupus nephritis patients with different demographic data in patients' group.

Data of the present study as regards serum lipoxin A4 level among lupus nephritis patients with different clinical data, showed that there was a statistically significant difference with low mean of serum lipoxin A 4 level among patients' group having fatigue and fever with $p$-value $<0.05$ (Table 4).
Table (4): Comparison of lipoxinA4 level among different clinical data of patients group.

\begin{tabular}{|c|c|c|c|c|}
\hline \multirow{2}{*}{ Variables } & \multicolumn{2}{|c|}{ Lipoxin A4 } & \multirow{2}{*}{$\begin{array}{c}p- \\
\text { value }\end{array}$} & \multirow{2}{*}{ Sig. } \\
\hline & Mean & юO & & \\
\hline \multicolumn{5}{|c|}{ Thrombosis: } \\
\hline No & 7.5 & 4.5 & 0.3 & NS \\
\hline Yes & 9.4 & 4.6 & & \\
\hline \multicolumn{5}{|l|}{ Vasculitis: } \\
\hline No & 7.9 & 4.3 & 0.4 & NS \\
\hline Yes & 6.7 & 5.5 & & \\
\hline \multicolumn{5}{|l|}{ Myalgia: } \\
\hline No & 8.1 & 4.9 & 0.3 & NS \\
\hline Yes & 6.6 & 3.5 & & \\
\hline \multicolumn{5}{|l|}{ Arthritis: } \\
\hline No & 7.5 & 5.1 & 0.6 & NS \\
\hline Yes & 8.1 & 3.6 & & \\
\hline \multicolumn{5}{|l|}{ Arthralgia: } \\
\hline No & 6.8 & 4.1 & 0.2 & NS \\
\hline Yes & 8.4 & 4.9 & & \\
\hline \multicolumn{5}{|l|}{ Nephritic: } \\
\hline No & 7.3 & 4.2 & 0.5 & NS \\
\hline Yes & 8.1 & 5.1 & & \\
\hline \multicolumn{5}{|c|}{ Motor affection: } \\
\hline No & 7.5 & 4.6 & 0.5 & NS \\
\hline Yes & 8.7 & 4.6 & & \\
\hline \multicolumn{5}{|c|}{ Sensory affection: } \\
\hline No & 7.7 & 4.3 & 0.9 & NS \\
\hline Yes & 7.9 & 8.2 & & \\
\hline \multicolumn{5}{|c|}{ Psychological affection: } \\
\hline No & 7.3 & 4.7 & 0.3 & NS \\
\hline Yes & 8.5 & 4.5 & & \\
\hline \multicolumn{5}{|c|}{ Weight loss: } \\
\hline No & 7.1 & 4.5 & 0.1 & NS \\
\hline Yes & 9.3 & 4.6 & & \\
\hline \multicolumn{5}{|l|}{ Fatigue: } \\
\hline No & 9.6 & 4.7 & 0.006 & $\mathrm{~S}$ \\
\hline Yes & 6.1 & 3.8 & & \\
\hline \multicolumn{5}{|l|}{ Fever: } \\
\hline No & 8.7 & 5.1 & 0.005 & $\mathrm{~S}$ \\
\hline Yes & 6.3 & 3.6 & & \\
\hline \multicolumn{5}{|c|}{ Blood pressures: } \\
\hline Normal & 7.5 & 3.2 & 0.08 & NS \\
\hline High & 7.7 & 4.9 & & \\
\hline
\end{tabular}

The current study results showed lower levels of serum lipoxin A4 in patients of lower $\mathrm{C} 4$ level $(7.5 \pm 4.5) \mathrm{ng} / \mathrm{ml}$ versus those of normal C4 level $(7.9 \pm 4.9) \mathrm{ng} / \mathrm{ml}$ yet they had no statistically significant differences $p=0.7$.

Also, the current study results showed lower levels of serum lipoxin $\mathrm{A} 4$ in patients of the positive anti ds-DNA (7.6 \pm 4.6$) \mathrm{ng} / \mathrm{ml}$ versus those of negative anti ds-DNA $(8.1 \pm 4.7) \mathrm{ng} / \mathrm{ml}$ but with no statistically significant differences $p=0.8$.

In addition, the results of renal biopsy showed that the lowest levels of lipoxin A 4 were found in patients with class IV $(7.1 \pm 4.4) \mathrm{ng} / \mathrm{ml}$ and relatively higher levels of lipoxin A4 were found in patients 
with Class V (10.4 \pm 5.9$) \mathrm{ng} / \mathrm{ml}$, but those results didn't reach statistically significant differences $p=0.3$.

Results of the current study showed that patients with chronic affection of renal biopsy exhibited the lowest level of serum lipoxin A 4 (6.8 \pm 4.1$)$ $\mathrm{ng} / \mathrm{ml}$ while patients with active affection showed the highest levels $(9.1 \pm 4.7) \mathrm{ng} / \mathrm{ml}$ and patients with active/chronic affection $(8.5 \pm 5.7) \mathrm{ng} / \mathrm{ml}$ yet it is to be noted that lipoxin A 4 level are suppressed in all classes as cut off value is $12.3 \mathrm{ng} / \mathrm{ml}$ but those results didn't reach statistically significant differences.

Data of our study revealed no statistically significant differences among patients receiving different drug categories as regard serum Lipoxin A 4 level.

Using the Spearman's rank correlation coefficient (rho) test for correlations and taking the 50 lupus nephritis patients as one group, there is weak positive correlation between serum Lipoxin A 4 level with proteinuria and blood pressure. On the opposite side, there is weak negative correlation between serum Lipoxin A 4 level with age, disease duration, renal duration of the disease, urea, creatinine, ESR and renal SLEDAI yet those correlations did not reach statistical significance (Table 5).

Table (5): Correlations between lipoxin A4 level and (demographic data, laboratory investigations and disease activity index among lupus nephritis patients).

\begin{tabular}{|c|c|c|c|}
\hline \multirow{2}{*}{ Variables } & \multicolumn{3}{|c|}{ Lipoxin A4 } \\
\hline & $r$ & $p$-value & Sig. \\
\hline \multicolumn{4}{|l|}{ Demographic data: } \\
\hline Age (years) & -0.02 & 0.8 & NS \\
\hline Disease duration (months) & -0.03 & 0.7 & NS \\
\hline Renal affection duration (months) & -0.14 & 0.3 & NS \\
\hline \multicolumn{4}{|l|}{ Kidney functions: } \\
\hline Urea & -0.1 & 0.3 & NS \\
\hline Creatinine (mg/dl) & -0.1 & 0.4 & NS \\
\hline 24 hour urinary protein $(\mathrm{gm} / \mathrm{dl})$ & 0.2 & 0.2 & NS \\
\hline \multicolumn{4}{|l|}{ Liver functions: } \\
\hline Albumin (gm) & 0.2 & 0.2 & NS \\
\hline AST (mg/dl) & 0.1 & 0.5 & NS \\
\hline ALT (mg/dl) & -0.1 & 0.4 & NS \\
\hline \multicolumn{4}{|l|}{ Other blood investigations: } \\
\hline $\mathrm{Hb}(\mathrm{gm} / \mathrm{dl})$ & 0.1 & 0.4 & NS \\
\hline Lymphocytes \% 3 & 0.09 & 0.5 & NS \\
\hline Platelet count $(10 / \mu \mathrm{L})$ & 0.1 & 0.3 & NS \\
\hline ESR & -0.008 & 0.9 & NS \\
\hline \multicolumn{4}{|l|}{ SLE disease activity index: } \\
\hline Renal (SLEDAI) & -0.07 & 0.6 & NS \\
\hline Total (SLEDAI) & 0.04 & 0.8 & NS \\
\hline \multicolumn{4}{|l|}{ Arterial blood pressure: } \\
\hline Systolic & 0.03 & 0.8 & NS \\
\hline Diastolic & 0.08 & 0.6 & NS \\
\hline
\end{tabular}

Regarding the Receiver Operating Characteristic curve (ROC) analysis to calculate the best cutoff point for lipoxin A4 that discriminates between control group and lupus nephritis patients group we found that the best cutoff point of lipoxin A 4 is $12.3 \mathrm{ng} / \mathrm{ml}$ at which probability of being true positive is $(76.5 \%)$ more than being false positive when repeat test 100 times with sensitivity $(81 \%)$ and specificity (60\%) Fig. (3).

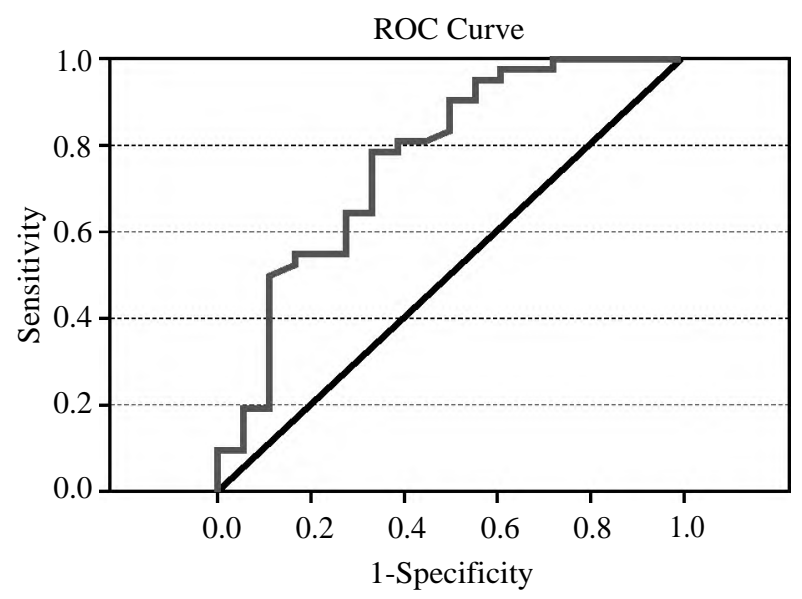

Fig. (3): Receiver Operating Characteristic curve (ROC curve)

\section{Discussion}

The aim of this study is to assess the level of serum lipoxin A4 as a diagnostic biomarker in cases of SLE complicated with lupus nephritis and to evaluate its relation to pathogenesis of lupus nephritis and renal disease activity.

Because kidney biopsies are not repeated at every flare, a noninvasive predictor of renal pathology would be very useful in choosing therapy. This approach to treatment represents a fundamental change from a reactive to a proactive paradigm and will require biomarkers that accurately predict SLE nephritis activity, pathology, and prognosis to guide therapeutic decisions. Many lupus nephritis biomarker studies have used cross-sectional cohorts to identify novel markers of disease activity. However; several studies examined lupus biomarker expression prospectively, to identify biomarkers that can predict the future course of lupus nephritis. In an effort to optimize current and future therapies, it is relevant to review these studies and their clinical implications [17]

Plasma and urinary measurement of lipoxins may be used to predict prognosis and response to therapy. It is likely that lipoxins and other bioactive anti-inflammatory lipids such as resolvins, protectins, maresins and nitrolipids play a significant role in other auto-immune diseases [18] . 
Based on the evidences presented above and the role of LXA 4 and LTs in inflammation, it is quite logical to suggest that a deficiency of LXA 4 and/or an excess of LTs initiate and perpetuate systemic and renal inflammation in lupus. Since, it is possible to estimate these compounds in the urine; we proposed that progression and flares of lupus and lupus nephritis are due to decreased production of LXA 4 and enhanced production of LTs by the renal tissue and/or infiltrating leukocytes and macrophages. These molecules can be detected and estimated in the urine and serum [19].

Plasma concentrations of LXA 4 could be compared to serum urea, creatinine and urinary protein values and wherever possible to renal biopsy findings to know the progression of renal lupus disease [18]. In our study we measured the serum level of LXA4 in fifty patients with SLE complicated by lupus nephritis in comparison to 10 healthy controls then we correlate the results of the study with demographic data, items of clinical examination, laboratory investigations, results of renal biopsy and drug history. Our results showed that lipoxin A4 level in cases was significantly suppressed than that of controls.

Mayadas et al., [20] reported that decreased LXA4 biosynthesis was associated with exaggerated neutrophil infiltration in patients with glomerulonephritis. Also, Kieran et al., [21] stated that Insufficiency of LXA 4 may be responsible for the patients with Henoch-Schoenlein Purpura (HSP) whose illness become more serious. In addition, Thomas et al., [22] reported that PMNs from Rheumatoid Arthritis (RA); patients generate diminished levels of lipoxins.

However, Wu SH et al., [19] found that expression levels of both LXA4 in leukocytes and glomeruli were up-regulated during the acute phase of disease, further peaking between days 10 and 14, and remained increased after 6 to 8 weeks of post streptococcal glomerulonephritis but this may prove that the self limiting character of post streptococcal glomerulonephritis is mostly due to elevated levels of lipoxin A4.

LXA4 is generated within the vascular lumen during glomerular inflammation by transcellular routes during neutrophil-platelet interactions and that adhesion of platelets and neutrophils through platelet P-selectin promotes transcellular LXA 4 biosynthesis in this setting. Exposure of neutrophils to LXA4 results in inhibited neutrophil trafficking to glomerulonephritic kidneys, suggesting that cellcell interactions may promote the generation of endogenous lipid derived inhibitors that act on leukocyte trafficking during the evolution of multicellular inflammatory responses to limit tissue destruction. In this regard, our results add to an expanding body of evidence implicating products of the 12-and 15-lipoxygenase pathways (lipoxins, 15-hydroxyeicosatetraenoic acid) as "braking signals" in the evolution of host defense and inflammatory responses [17].

Demographically our results showed that LXA 4 was suppressed in all patients regardless sex and age groups but interestingly patients above 30 years old showed more reduction of lipoxin A 4 levels. Our data come in accordance with Gangemi et al., [23] who have reported that generation of LXA4 can decrease with increased age that urinary levels of LXA4 was decreased while that of LTs (leukotrienes) increased in volunteers aged from 30 to over 100 years leading to a profound unbalance of the LXA(4)/LTs ratio these results suggest that endogenous anti-inflammatory mechanisms become less efficient with age that could result in increased susceptibility to inflammatory disorders with advancing age.

Regarding clinical data (history and examination) our results illustrated that there is statistically significant differences with low mean of lipoxin A4 level among lupus patients having fatigue and fever but the rest of history and clinical examination parameters showed no statistically significant differences. In addition, our results showed that lipoxin A4 level is positively correlated with proteinuria and blood pressure and on the opposite side it is negatively correlated with age, disease duration, renal duration of the disease, urea, creatinine, ESR and renal SLEDAI yet those correlations did not reach statistically significant differences.

Wu SH et al., [19] stated that LXA 4 and the amounts of proteinuria brought out a negative correlation with lipoxin A 4 plasma level. Also, another study discovered that concordant with the gradually increased proteinuria, the levels of urinary LXA4 gradually decreased and the levels of urinary Leukotriene E4 and Leukotriene B4 gradually increased [24].

Regarding renal biopsy results we discovered that the results of renal biopsy classes showed that lowest levels of lipoxin A 4 were found in patients with class IV and relatively higher levels of lipoxin A4 were found in patients with Class V. These results showed that patients with chronic affection of renal biopsy exhibited the lowest level of lipoxin A4 while patients with active affection showed the 
highest levels of lipoxin A4, but these results didn't reach statistically significant differences.

Börgeson et al., [25] assessed the role and mechanism of lipoxins in attenuating profibrotic responses to Transforming Growth Factor Beta 1 (TGF(3 1). They demonstrated that LXA 4 potently represses the expression of key markers of renal fibrosis induced by TGF- $\beta 1$ they provided in vivo evidence that the protective effects of lipoxin against renal fibrosis.

Despite aggressive immunosuppression, our ability to control severe SLE glomerulonephritis remains unsatisfactory. Treatment with intravenous or oral cyclophosphamide followed by maintenance immunosuppression with azathioprine or Mycophenolate Mofetil (MMF) yields complete and partial remissions in less than $50 \%$ of patients after 6 months.

Similar outcomes are seen when MMF is used for both induction and maintenance therapy. To make matters worse, these regimens are highly toxic and often poorly tolerated. The ideal approach to improve the outcome of SLE nephritis is to develop new drugs that are more disease specific, better tolerated, and less toxic. Although this has been the goal of several recent large, randomized, prospective clinical trials, none of these trials was successful in demonstrating a better way to treat lupus nephritis. Thus, for the foreseeable future, currently available drugs need to be used more effectively. It is conceivable that complete remission rates could be improved, and less cytotoxic therapy would be needed if flares could be anticipated and preemptive treatment started. Additionally, modification of drug dose and duration of therapy based on the predicted outcome of a flare (e.g., development of Chronic Kidney Disease [CKD] would be expected to improve treatment efficacy and reduce toxicity [18].

Current treatments for this disease are limited by life-threatening side effects. Lipoxins and Aspirin-Triggered Lipoxins (ATL) offer therapeutic potential, by switching the cellular response from inflammation in favor of resolution, with dissipation of local gradients of proinflammatory mediators, inhibition of further PMN recruitment, enhanced clearance of recruited inflammatory cells, inhibition of mesangial cell proliferation, and potential regulation of matrix accumulation in this context [26]

Regarding drug therapy there were no significant statistical difference between lipoxin A 4 level and drug therapy of patients. Pankaj et al., [27] stated that LXA 4 production is stimulated by lipopolysaccarides, and it is suppressed by dexamethasone. Moreover, inhaled dexamethasone significantly suppressed lipopolysaccarides-induced increases in LXA 4 in lung alveoli. Another study stated that steroids suppression of LXA 4 levels may contribute to persistent airway neutrophilic inflammation since LXA4 can inhibit LTB 4-induced chemotaxis, adhesion and transmigration [28]

Lipoxin A4 level at concentration of $12.3 \mathrm{ng} / \mathrm{ml}$ showed the best cutoff value where the sensitivity is $(81 \%)$ and specificity was $(60 \%)$ calculated by ROC curve.

\section{Conclusion:}

Our study was performed to assess serum LXA 4 levels in lupus nephritis patients and compare them with control cases. Also, to correlate serum LXA 4 levels in lupus nephritis patients with the activity and severity of renal disease. Our study showed highly significant statistical decrease between case versus control regarding level of lipoxin A4. Moreover, there was no significant statistical correlation with various clinical and laboratory data, as well as renal biopsy and disease activity index.

Finally, we conclude that lipoxins A 4 in low levels could be used as a noninvasive diagnostic biomarker for renal involvement in SLE patients. Serum lipoxin A4 could not be correlated with activity or severity of renal involvement in SLE patients. Further studies are recommended in trial of therapeutic application of lipoxins in treatment of SLE.

We therefore recommend performing longitudinal studies with larger number of patients to follow changes in serum LXA 4 levels before, during, and following SLE flares, and comparing their levels with other proinflammatory molecules such as LTs. We also recommend assessment of urinary LXA 4 as it may be more valuable than serum LXA4 in reflecting disease activity as well as severity of renal involvement in SLE and comparing it with serum LXA4 level.

\section{References}

1- GIULIANA M.C., La PAGLIA, MARIA C. LEONE GEMMA LEPRI, ROBERTA VAGELLI, ELEONORA VALENTINI, ALESSIA ALUNNO and CHIARA TANI: One year in review 2017: Systemic lupus erythematosus. Clin. Exp. Rheumatol., 35: 551-61, 2017.

2- JULIE COUTURE and EARL D. SILVERMAN: Update on the pathogenesis and treatment of childhood-onset systemic lupus erythematosus. Curr. Opin. Rheumatol., Sep., 28 (5): 488-96, 2016.

3- LOPES S.R.M., GORMEZANO N.W.S., GOMES R.C., AIKAWA N.E., et al.: Outcomes of 847 childhood-onset 
systemic lupus erythematosus patients in three age groups. Lupus. Aug., 26 (9): 996-1001, 2017.

4- RIVAS-LARRAURI and YAMAZAKI-NAKASHIMADA Systemic lupus erythematosus: Is it one disease? Reumatol Clin., Sep.-Oct., 12 (5): 274-81, 2016.

5- JONATAN LEFFLER, ANDERS A. BENGTSSON and ANNA M. BLOM: The complement system in systemic lupus erythematosus: An update. Ann. Rheum. Dis., Sep., 73 (9): 1601-6, 2014.

6- GUETTROT-IMBERT G., MOREL N., Le GUERN V., PLU-BUREAU G., FRANCES C. and COSTEDOATCHALUMEAU N.: Pregnancy and contraception in systemic and cutaneous lupus erythematosus. Ann. Dermatol. Venereol., Oct., 143 (10): 590-600, 2016.

7- CHEN F., LI Z., LI R. and LI Y.: Whole genome sequencing of a monozygotic twin discordant for systemic lupus erythematosus. Mol. Med. Rep., Jun., 17 (6): 83 91-6, 2018.

8- ALMAANI S., MEARA A. and ROVIN B.H.: Update on Lupus Nephritis. Clin. J. Am. Soc. Nephrol., May 8, 12 (5): 825-35, 2017.

9- TROTTER K., CLARK M.R. and LIARSKI V.M.: Overview of pathophysiology and treatment of human lupus nephritis. Curr. Opin. Rheumatol., Sep., 28 (5): 460-7, 2016.

10 - REGUNATHAN-SHENK R. and RADHAKRISHNAN J.: Pathogenesis of SLE Nephritis in the Era of Precision Medicine. Curr. Rheumatol. Rev., 14 (2): 140-4, 2018.

11-ROMANO M., CIANCI E., SIMIELE F. and RECCHIUTI A.: Lipoxins and aspirin-triggered lipoxins in resolution of inflammation. Eur. J. Pharmacol., Aug. 5, 760: 49-63, 2015.

12- CHANDRASEKHARAN J.A. and SHARMA-WALIA N.: Lipoxins: Nature's way to resolve inflammation. J. Inflamm. Res., Sep. 30, 8: 181-92, 2015.

13- SERHAN C.N., CHIANG N., DALLI J. and LEVY B.D.: Lipid mediators in the resolution of inflammation. Cold Spring Harb Perspect Biol. Oct. 30, 7 (2): a0163 11, 2014.

14- BEVRA H. HAHN, MAUREEN A. MCMAHON, ALAN WILKINSON, W. DEAN WALLACE, DAVID I. DAIKH, JOHN D. FITZGERALD, et al.: American College of Rheumatology Guidelines for Screening, Treatment, and Management of Lupus Nephritis. Arthritis Care \& Research Vol. 64, No. 6, June, pp. 797- 808, 2012.

15- CECCARELLI F., PERRICONE C., MASSARO L., CIPRIANO E., ALESSANDRI C., SPINELLI F.R., VALESINI G. and CONTI F.: Assessment of disease activity in Systemic Lupus Erythematosus: Lights and shadows. Autoimmun. Rev., Jul., 14 (7): 601-8, 2015.

16- WEENING J.J., D'AGATI V.D., SCHWARTZ M.M., SESHAN S.V., ALPERS C.E. and APPEL G.B.: The classification of glomerulonephritis in systemic lupus erythematosus revisited. J. Am. Soc. Nephrol., 15 (2): 241-50, 2004.

17-ARRIENS C., WREN J.D., MUNROE M.E. and MOHAN C.: Systemic lupus erythematosus biomarkers: The challenging quest. Rheumatology (Oxford). Apr. 1, 56 (Suppl1): i32-i45, 2017.

18- DAS U.N.: Lipoxins as biomarkers of lupus and other inflammatory conditions. Lipids Health Dis., 10: 76, 2011.

19- WU S.H., LIAO P.Y., YIN P.L., ZHANG Y.M. and DONG L.: Elevated expressions of 15-lipoxygenase and lipoxin A4 in children with acute poststreptococcal glomerulonephritis. Am. J. Pathol., 174: 115-22, 2009.

20- MAYADAS T.N., MENDRICK D.L., BRADY H.R., et al.: Acute passive antiglomerular basement membrane nephritis in P-selectin-deficient mice. Kidney Int., 49: 1342-9, 1996.

21- KIERAN N.E., MADERNA P. and GODSON C.: Lipoxins: Potential anti-inflammatory, proresolution, and antifibrotic mediators in renal disease. Kidney Int., Apr., 65 (4): 114554, 2004.

22- THOMAS E., et al.: Conversion of endogenous arachidonic acid to 5,15 dihete and lipoxins by polymorphonuclear cells from patients with rheumatoid arthritis. Inflamm. Res., 44: 121-4, 1995.

23- GANGEMI S., PESCARA L., D'URBANO E., BASILE G., NICITA-MAURO V., DAVİ G. and ROMANO M.: Aging is characterized by a profound reduction in antiinflammatory lipoxin A4 levels. Exp. Gerontol., Jul., 40 (7): 612-4, 2005.

24- WU S.H., LIAO P.Y., YIN P.L., ZHANG Y.M. and DONG L.: Inverse temporal changes of lipoxin A4 and leukotrienes in children with Henoch-Schönlein purpura. Prostaglandins Leukot Essent Fatty Acids, 80: 177-83, 2009.

25- BÖRGESON E., DOCHERTY N.G., MURPHY M., RODGERS K., RYAN A., O'SULLIVAN T.P., GUIRY P.J., GOLDSCHMEDING NS D.F. and GODSON C.: Lipoxin A4 and benzo-lipoxin A4 attenuate experimental renal fibrosis. FASEB J., 25: 2967-79, 2011.

26- SERHAN C.N. : Lipoxins and aspirin-triggered 15-epilipoxins are the first lipid mediators of endogenous antiinflammation and resolution. Prostaglandins Leukot Essent Fatty Acids. Sep.-Oct., 73 (3-4): 141-62, 2005.

27- PANKAJ K. BHAVSAR, BRUCE D. LEVY, MARK J. HEW, MICHAEL A. PFEFFER, SHAMSAH KAZANI, ELLIOT ISRAEL and KIAN FAN CHUNG: Corticosteroid suppression of lipoxin A4 and leukotriene B4 from alveolar macrophages in severe asthma. Respir. Res., 11 (1): 71, 2010.

28- SERHAN C.N.: Resolution phase of inflammation: Novel endogenous anti-inflammatory and proresolving lipid mediators and pathways. Annu. Rev. Immunol., 25: 10137, 2007. 


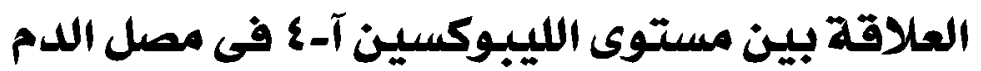

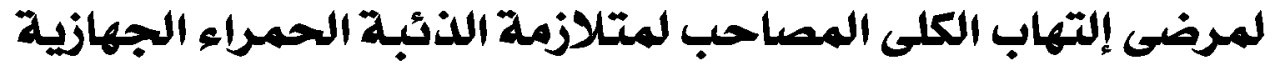

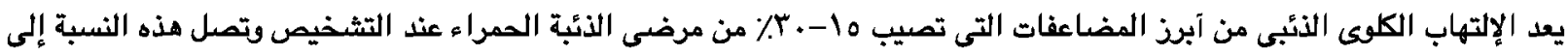

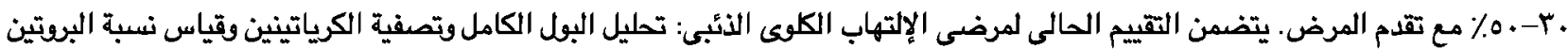

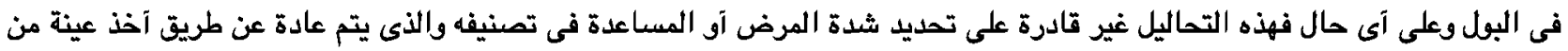

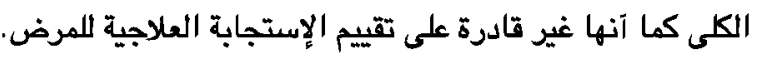

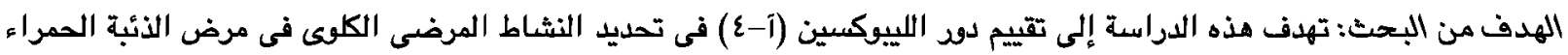

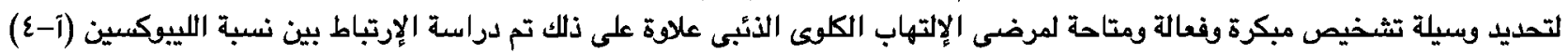

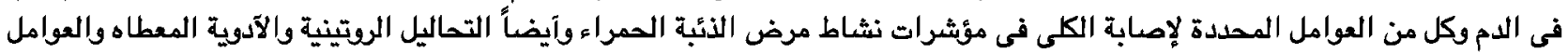
الديموغرافية في مرضى الأئبة الحمراء.

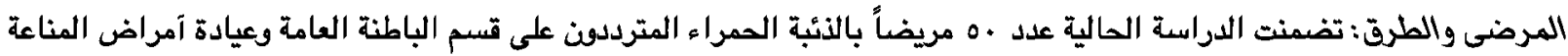

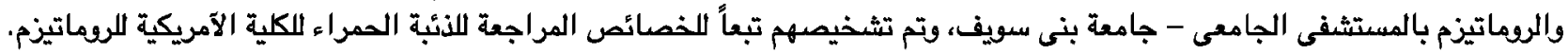

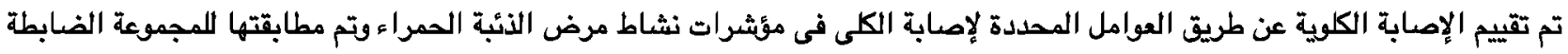

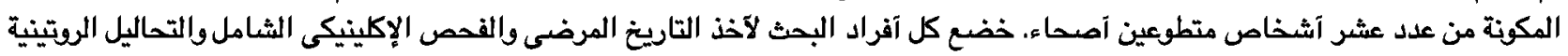
والتاريخ الدوائي، وقياس نسبة اللييوكسين (آ-ع) فى الدم.

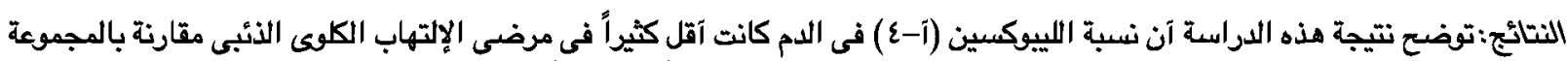

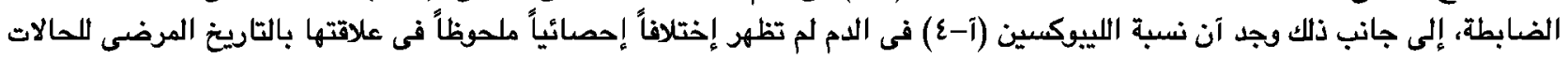

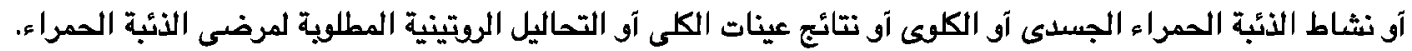

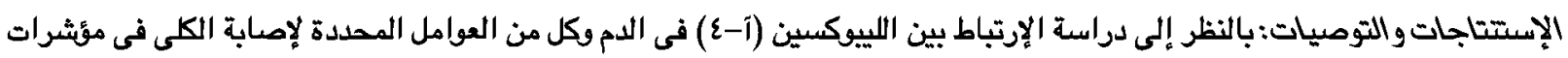

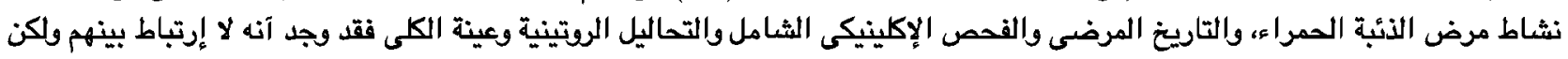

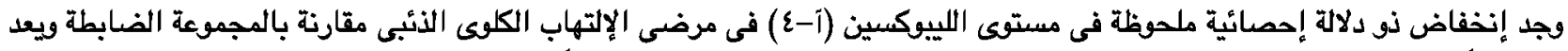

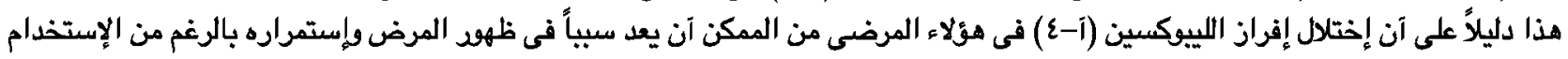

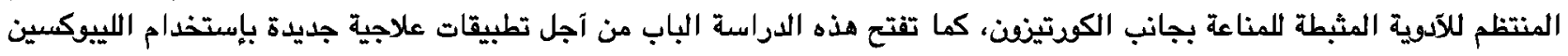

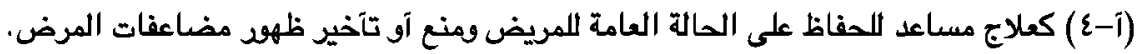

